\title{
Effects of the Physical Environment on Cognitive Load and Learning: Towards a New Model of Cognitive Load
}

Citation for published version (APA):

Choi, H-H., van Merrienboer, J. J. G., \& Paas, F. (2014). Effects of the Physical Environment on Cognitive Load and Learning: Towards a New Model of Cognitive Load. Educational Psychology Review, 26(2), 225-244. https://doi.org/10.1007/s10648-014-9262-6

Document status and date:

Published: 01/06/2014

DOI:

10.1007/s10648-014-9262-6

Document Version:

Publisher's PDF, also known as Version of record

Document license:

Taverne

Please check the document version of this publication:

- A submitted manuscript is the version of the article upon submission and before peer-review. There can be important differences between the submitted version and the official published version of record.

People interested in the research are advised to contact the author for the final version of the publication, or visit the DOI to the publisher's website.

- The final author version and the galley proof are versions of the publication after peer review.

- The final published version features the final layout of the paper including the volume, issue and page numbers.

Link to publication

\footnotetext{
General rights rights.

- You may freely distribute the URL identifying the publication in the public portal. please follow below link for the End User Agreement:

www.umlib.nl/taverne-license

Take down policy

If you believe that this document breaches copyright please contact us at:

repository@maastrichtuniversity.nl

providing details and we will investigate your claim.
}

Copyright and moral rights for the publications made accessible in the public portal are retained by the authors and/or other copyright owners and it is a condition of accessing publications that users recognise and abide by the legal requirements associated with these

- Users may download and print one copy of any publication from the public portal for the purpose of private study or research.

- You may not further distribute the material or use it for any profit-making activity or commercial gain

If the publication is distributed under the terms of Article $25 \mathrm{fa}$ of the Dutch Copyright Act, indicated by the "Taverne" license above, 


\title{
Effects of the Physical Environment on Cognitive Load and Learning: Towards a New Model of Cognitive Load
}

\author{
Hwan-Hee Choi • Jeroen J. G. van Merriënboer • \\ Fred Paas
}

Published online: 3 April 2014

(C) Springer Science+Business Media New York 2014

\begin{abstract}
Although the theoretical framework of cognitive load theory has acknowledged a role for the learning environment, the specific characteristics of the physical learning environment that could affect cognitive load have never been considered, neither theoretically nor empirically. In this article, we argue that the physical learning environment, and more specifically its effects on cognitive load, can be regarded as a determinant of the effectiveness of instruction. We present an updated version of the cognitive load model of Paas and Van Merriënboer (Educational Psychology Review, 6:351-371, 1994a), in which the physical learning environment is considered a distinct causal factor that can interact with learner characteristics, learning-task characteristics, or a combination of both. Previous research into effects of the physical learning environment on cognitive performance that could inspire new cognitive load research is discussed, and a future research agenda is sketched.
\end{abstract}

Keywords Cognitive load theory · Physical learning environment · Instructional design

\section{Introduction}

In the model of the construct of cognitive load presented by Paas and Van Merriënboer (1994a), learner characteristics, learning-task characteristics, and their interactions were identified as the main factors causing cognitive load. Imagine two groups of students learning to solve a new type of complex problem. One group learns by solving conventional problems and the other group by studying well-designed worked examples. In each group, there are students with some prior knowledge of the problem domain as well as students without any prior

\footnotetext{
H.-H. Choi $(\bowtie) \cdot$ F. Paas

Institute of Psychology, Erasmus University Rotterdam, P.O. Box 1738, 3000 DR Rotterdam, The

Netherlands

e-mail: choi@fsw.eur.nl

J. J. G. van Merriënboer

Department of Educational Development and Research, Maastricht University, Maastricht, The Netherlands

F. Paas

Early Start Research Institute, University of Wollongong, Wollongong, Australia
} 
knowledge. Based on cognitive load theory (CLT; Paas et al. 2003a, 2004; Sweller et al. 1998, 2011), it would be easy to predict the cognitive load and learning performance of both groups of learners in both conditions, using the theoretical and empirical evidence on the specific combination of learner characteristics (i.e., prior knowledge), learning-task characteristics (i.e., conventional problems vs. worked examples), and interactions between both (using the "expertise-reversal effect"; Kalyuga et al. 2003).

However, what would happen with our CLT-based predictions if we knew that the students had to learn in a noisy environment? Although it is clear that characteristics of the physical environment (e.g., high level of noise or high temperature) will affect cognitive load and learning, a prediction based on CLT would be difficult to make. In fact, with the exception of research into the processing of task-irrelevant details in the physical learning environment (Plass et al. 2013; Rey 2012, 2014), the role of the physical environment has largely been ignored in cognitive load research.

This article aims at a reconceptualization of the role of the environment in a general model of cognitive load. The first section revisits the original model of cognitive load presented by Paas and Van Merriënboer (1994a), which describes task characteristics, learning-task characteristics, and their interactions as causal factors of cognitive load. The second section proposes a revised model. In this revised model, the physical learning environment is considered as a distinct causal factor of cognitive load by redefining the term "environment" in terms of its physical properties (i.e., the physical learning environment) and by separating the characteristics of the physical learning environment from the learning-task characteristics. The third section explores the effects of the physical environment on cognitive load and learning, making a distinction between cognitive effects, physiological effects, and affective effects. The fourth section discusses how changes in the physical environment can have a positive impact on cognitive load and learning; here, a distinction is made between taskenvironment interactions, learner-environment interactions, and three-way interactions between task, learner, and environment. The fifth and final section presents theoretical and practical implications of the revised model and its limitations.

\section{The Original Model of Cognitive Load}

CLT (Ayres and Paas 2012; Paas et al. 2003a, 2004; Paas and Sweller 2012; Paas and Van Merriënboer 1994a; Sweller et al. 1998; Van Merriënboer and Sweller 2005, 2010) is a theoretical framework based upon our knowledge of human cognitive architecture. This architecture consists of a long-term memory (LTM) and a working memory (WM). Contrary to LTM, WM is severely limited in both capacity (Cowan 2001, this issue; Miller 1956) and duration (Peterson and Peterson 1959); people can hold no more than five to nine information elements for no more than $20 \mathrm{~s}$, and even less when the information elements interact. When dealing with unfamiliar information, the limits of WM are far below the requirements of complex cognitive tasks; and without LTM, the human cognitive architecture would only permit performance of relatively easy cognitive tasks. However, the limits of WM are eliminated when it deals with familiar information organized in cognitive schemas in LTM. Cognitive schemas are used to store and organize knowledge by incorporating or chunking multiple elements of information into a single element with a specific function. Their incorporation in a schema means that only one element must be processed when a schema is brought from LTM to WM to govern activity. Skilled performance develops through the building of increasing numbers of ever more complex schemas by combining elements consisting of lower level schemas into higher level schemas (i.e., schema construction). If the learning process has occurred over a long period of time, a schema may incorporate a huge 
amount of information. The automation of those schemas (i.e., schema automation), so that they can be processed unconsciously, further reduces the load on WM (i.e., cognitive load). Because a schema can be treated by WM as a single element or used unconsciously (i.e., bypass WM) after automation, the limitations of WM disappear for more knowledgeable learners when dealing with previously learned information stored in LTM. As a result, once information is stored in LTM, WM can handle a complex material that exceeds its capacity prior to the information being stored.

Within CLT, two main categories of cognitive load are identified, namely intrinsic load and extrinsic load (e.g., Paas et al. 2003b). Whereas intrinsic cognitive load is determined by the intrinsic nature of the learning task (i.e., the number of interacting information elements), extrinsic cognitive load is determined by the way in which the learning task is presented (i.e., instructional design). Extrinsic cognitive load can be either ineffective (i.e., extraneous cognitive load) or effective (i.e., germane cognitive load) for learning. In the most recent version of CLT (Kalyuga 2011; Sweller 2010; Sweller et al. 2011; see also Leppink et al. 2013; Leppink et al. 2014), only intrinsic and extraneous cognitive loads are distinguished. This new distinction is based on the assumption that manipulations to increase germane load, such as increasing practice problem variability (e.g., Paas and Van Merriënboer 1994b) or adding process information to worked examples (e.g., Van Gog et al. 2006), actually increase intrinsic load by adding interactive elements to the learning task. In this new conception, WM resources allocated to deal with intrinsic cognitive load are called "germane resources."

The original model of the construct of cognitive load proposed by Paas and Van Merriënboer (1994a) is presented in Fig. 1. A distinction is made between causal factors and assessment factors of cognitive load, corresponding to factors that affect cognitive load and factors that can be measured to assess cognitive load. With regard to its measurement, cognitive load can be conceptualized in the dimensions of mental load, mental effort, and performance. According to Paas and Van Merriënboer (1994a), a cognitive load assessment based on mental load is a task-centered, subject independent dimension, which is solely based on the characteristics of the task (e.g., number of interacting information elements). Mental

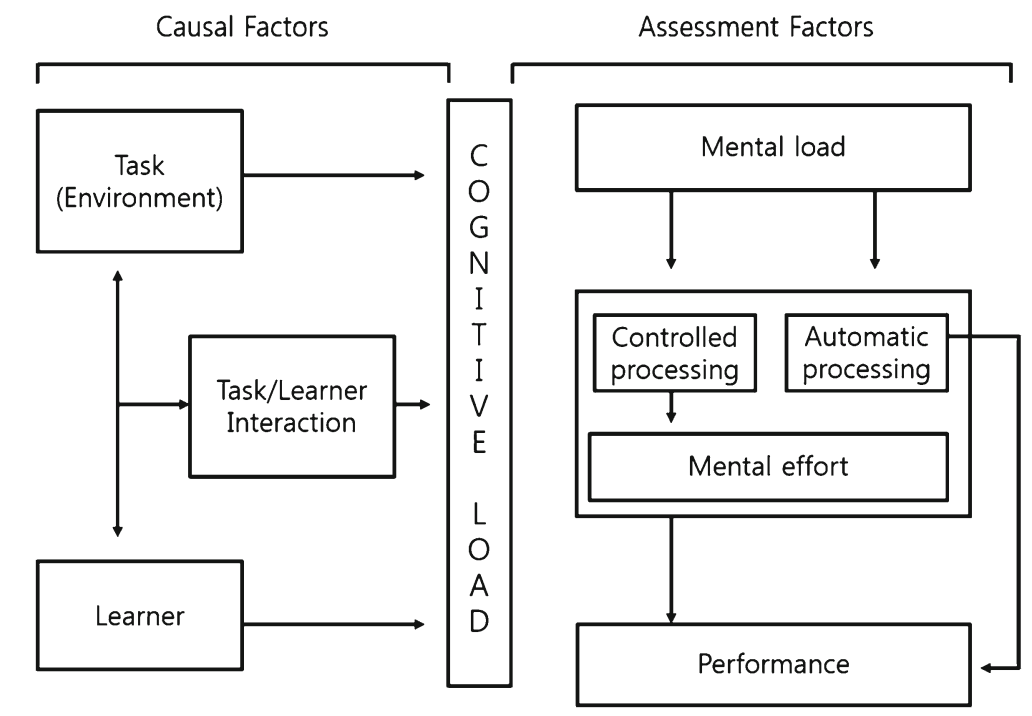

Fig. 1 The original model of construct of cognitive load. Adapted from Paas and Van Merriënboer (1994a), Educational Psychology Review, 6, p. 3. Copyright 1994 by Plenum Publishing Corporation 
effort is considered a human-centered dimension, which refers to the amount of capacity or resources that is actually allocated by the learner to accommodate the task demands. A cognitive load assessment based on mental effort is believed to reflect the amount of controlled processing the learner is engaged in (Schneider and Shiffrin 1977; Shiffrin and Schneider 1977). Consequently, it is assumed to reflect the interaction between learner and learning-task characteristics. The level of performance can also be used to assess the cognitive load. For similar learners, faster task performance with less effort can be considered to indicate a lower cognitive load than slower task performance with more errors.

With regard to the causal factors, task (environment) characteristics, learner characteristics, and their interactions are identified. It should be noted that in real learning environments, both characteristics always interact: There is no learning without a learner, and there is no learner if there is nothing to learn. So, although learner and learning-task characteristics can be defined in isolation, in practice, they are always related. Yet, in experimental designs, it is possible to manipulate only one factor and keep the other factor constant. In some CLT studies, learner characteristics are assumed to be constant, because participants are selected from a homogeneous pool and randomly assigned to experimental conditions that differ only regarding a learning-task characteristic (e.g., conventional problem solving vs. worked example study). To the best of our knowledge, there are no CLT studies that have varied learner characteristics, while keeping the learning task constant. Other CLT studies have focused on the interaction between learning-task characteristics and learner characteristics. The most notable examples of such studies have looked at the interaction between task characteristics and learner expertise, that is, the expertise-reversal effect (e.g., Kalyuga et al. 2003; Kalyuga et al. 2012) and learning-task characteristics and learner age (e.g., Paas et al. 2001; Van Gerven et al. 2006).

Task characteristics that have been considered in CLT research were mostly related to the nature of the practice problems. Most of the early cognitive load research focused exclusively on task characteristics and resulted in CLT effects such as the goal-free effect (e.g., Ayres 1993; Sweller 1988), the worked example effect (e.g., Paas and Van Merriënboer 1994b; Sweller 1988), the completion effect (e.g., Paas 1992; Van Merriënboer 1990; Van Merriënboer and De Croock 1992), and the variability effect (e.g., Paas and Van Merriënboer 1994b). Learner characteristics that have been considered in CLT research are expertise (e.g., Kalyuga et al. 2003; Kalyuga et al. 2012), age (e.g., Paas et al. 2001; Van Gerven et al. 2006), motivation (e.g., Paas et al. 2005), and affect (e.g., Fraser et al. 2012).

\section{Towards a New Model of Cognitive Load}

In the original model of Paas and Van Merriënboer (1994a), the task characteristics are classified as the cognitive demands imposed not only by the learning task but also by the learning environment. However, whereas the effects of the demands imposed by the relationships between the learning task and the characteristics of the learner have been studied extensively as causal factors of cognitive load (see left part of the model in Fig. 1), the effects of the demands imposed by the physical learning environment have not been taken into consideration in cognitive load research. Similarly, the associated measurements of the cognitive load effects (i.e., assessment factors; see right part of the model in Figure 1) have only been studied for the relationships between the learning task and the learner characteristics, without considering the physical learning environment per se.

A new model of cognitive load needs to describe the physical properties of learning materials or the physical environment in which the learning information should be expressed and presented. Therefore, we argue that in identifying the environment-related causal factors of cognitive load, the physical properties of the environment should be primarily considered, the 
conceptual meaning of the task characteristics needs to be narrowly redefined (e.g., intrinsic task difficulties or the manner of instructional design), and the factors "learning task" and "learning environment" need to be disentangled. In order to realize this, we propose a revised version of the construct of cognitive load as presented in Fig. 2.

In the revised model, the factors learning task and learning environment are disentangled. The term physical learning environment is proposed instead of environment or learning environment in order to avoid any ambiguity. Under the assumption that learning tasks are always learned by learners in a learning environment, the physical learning environment is depicted as a factor that embraces task and learner characteristics (see the left part of Fig. 2). The physical learning environment refers to the whole range of physical properties of a place where teaching and learning takes place. These include physical characteristics of learning materials or tools (e.g., texture, color, size, shape, weight, and sound), the physical attributes of the built environment (e.g., volume, density, lighting conditions, arrangement, and thermal conditions), natural spaces, and the physical presence of other people. It covers sensory stimuli from the environment that can be perceived by human senses, that is, vision, hearing, smell, taste, touch, temperature, and balance. In the new model, the task characteristics are redefined

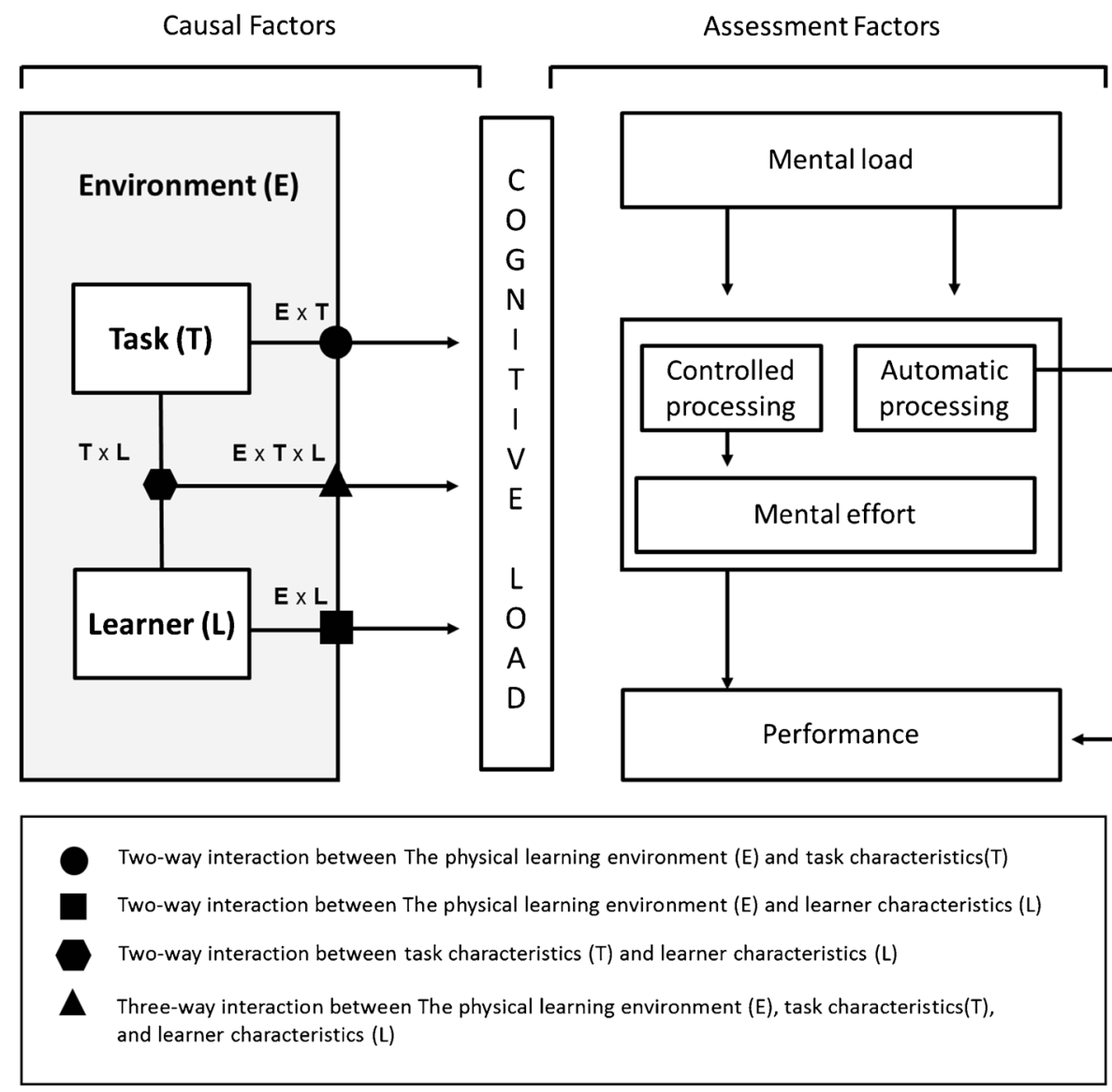

Fig. 2 The construct of cognitive load. $E$ the physical learning environment, $T$ learning task, $L$ learner. Adapted and revised from Paas and Van Merriënboer (1994a), Educational Psychology Review, 6, p. 3. Copyright 1994 by Plenum Publishing Corporation 
in a more narrow meaning, which refers to the intrinsic task difficulty, the type of task, or the manner of instructional design in learning material according to the conceptual distinctions made between task and environment. Although the new factor interacts with the characteristics of the task (and the learner), it is clearly separated from the causal factor 'learning task'.

With regard to this theoretical distinction, however, it should be noted that in practice, it is not always simple to distinguish the physical learning environment from the learning task. Consider, for instance, a computer-based learning task in a computer lab that can also be called a computer-based learning environment. In this case, the computer-based learning environment mainly refers to the computerized learning task, but it also reflects its physical properties such as the background color of the computer screen, the furniture (desk and chair) used by the learner, and even the physical properties of the computer lab. Furthermore, some elements of the environment (i.e., tools and other objects) should be regarded as part of the learning task when they are essential for learning. For example, the stethoscope and the patient are not just seen as the environment for medical students learning how to perform chest auscultation on a patient. In the same manner, if a learner is allowed to use a pocket calculator to solve a math problem, the calculator should be regarded as not just a physical object in the environment but as a learning tool which is an essential part of the task. In addition, some instructional designs include elements of the environment that are not an essential part of the learning task. The seductive details or coherence effect (Moreno and Mayer 2000; Plass et al. 2013; Rey 2012; Um et al. 2012; for a review, see Rey 2014), for example, refers to the interference from adjuncts that are not essential to achieve the learning goal, but nonetheless, these adjuncts (e.g., music, illustrations) are sometimes environmental stimuli designed by instructional designers.

The view that some elements in the physical environment actually belong to the cognitive domain of the task has led some researchers to assert the claim that cognition can be extended beyond a brain to be distributed over a system of people and objects within a task (see, Beer 2000; Clark and Chalmers 1998; see also, Wilson 2002, for a discussion). This assumption of distributed cognition suggests that our cognitive processing does not reside solely inside the brain, but instead is distributed and flowed across the individual and the physical environment (e.g., "extended mind": Clark and Chalmers 1998). Tools in the physical environment such as pocket calculators and whiteboards can be used as an external cognitive processor to collect and share the knowledge in both individual and collaborative learning (Dillenbourg and Traum 1997). Considering the learning aids in the ordinary classroom, pencil, paper, pocket calculator, and white board can be used as off-loading devices when learners want to solve a problem easily or retain information longer. If a learning task has a cognitively demanding procedure (e.g., lengthy training) or poor solving methods (e.g., calculating multiple numbers without a calculator), learners can handle their limited cognitive resources more efficiently by offloading parts of the cognitive task onto tools that are available in the physical environment (Wilson 2002).

How could we next identify the influence of environmental demands on learning especially within the CLT framework? Although there are no empirical studies in the context of CLT that considered cognitive load imposed by characteristics of the physical learning environment, there exists an extensive body of research outside CLT research on the influence of the physical environment on behavior, attitudes, and performance of both teachers and students (for reviews, see Evans 2006; Jamieson et al. 2000; Mendell and Heath 2005; Rivlin and Weinstein 1984; Tanner 2000, 2008; C. S. Weinstein 1979). At a basic level, the impact of the environment on cognitive processing can be clearly illustrated by the fact that identical objects can be perceived differently depending on the environment in which they are presented. For example, the visual illusion created by Hermann Ebbinghaus (see Titchener, 1901, p. 169., figure 52-3) shows that a central circle is perceived to be smaller when it is surrounded by 
larger circles than when it is surrounded by smaller circles. Similar observations of the effects of the environment have been found for the perception of lightness, weight, temperature, loudness, and flavor (e.g., Anderson and Winawer 2005; Marks et al. 2012).

Although researchers have proposed different explanations as to whether and how environmental factors affect learning, there are few theories based on the cognitive mechanisms underlying the effects of the physical learning environment. We argue that the theoretical framework of CLT, which provides human cognitive architecture-based interpretations for the instructional effectiveness of particular instructional designs, could provide an explanation of prior research findings as well as generate new research on this topic. In the next section, we will first discuss effects the physical environment might have on cognitive load and learning.

\section{Effects of the Physical Environment}

The next three sections discuss existing findings on the relationship between the physical learning environment and performance, showing that the physical environment may affect cognitive load and learning. Three types of effects of the physical environment are distinguished: cognitive effects, physiological effects, and affective effects. Whereas this is a useful theoretical distinction, it should be noted beforehand that it is often difficult to determine the influence of the physical learning environment on learning because of its complex multidimensional character (Higgins et al. 2005). The cognitive, physiological, and affective effects of the physical environment on learning may be closely intertwined (e.g., Evans and Stecker 2004).

\section{Cognitive Effects of the Physical Learning Environment}

Empirical studies have clearly shown that environmental stimuli from the physical learning environment can impose a load on learners' WM. Noise, whether visual or auditory, can be considered as a typical irrelevant environmental stimulus that takes limited WM resources away from the learners' cognitive process. An empirical demonstration of the role the environment plays in cognitive performance is the finding in the field of forensic psychology that excluding irrelevant stimuli from the environment through eye-closure reduces unproductive WM load and improves performance on eyewitness memory tasks by freeing WM resources that would otherwise have been involved in monitoring the environment (e.g., Vredeveldt et al. 2011). Glenberg et al. (1998) provided another demonstration of this phenomenon in the visual system by showing that memory retrieval could be improved when subjects averted their gaze from their environmental surroundings during cognitively difficult tasks. In fact, gaze aversion has been identified as a way of managing the WM load associated with the processing of visual environmental information (e.g., Doherty-Sneddon and Phelps 2005). The irrelevant speech effect (e.g., Salamé and Baddeley 1982, 1986) is a well-known example of this phenomenon in the auditory system, which refers to the interference from irrelevant auditory items (e.g., background speech or white noise) during immediate recall tests. Using positron emission tomography, Gisselgard and colleagues identified that neuro-physiological responses to the impact of irrelevant auditory stimuli (pseudo-words speech or white noise) are related to increased or decreased activations in regions of the brain associated with WM functioning (Gisselgard et al. 2003; Gisselgard et al. 2004).

The effect of the physical learning environment on cognition can also be regarded from a context-dependent memory perspective, which generally refers to the finding of better memory performance when the (physical) learning and test environment are similar than when they 
differ (for a review; see S. M. Smith and Vela 2001). Memory retrieval is usually brought about as a result of the integration of incoming environmental information with the "memory network" driven by that information (Tulving and Thomson 1973). Due to automatic (unconscious) target-context binding, environmental stimuli (e.g., smell, color, locations) are encoded as part of the memory trace (i.e., cognitive schema) and can be used as contextual cues to retrieve other information encoded at the same environment. A well-known demonstration of the effect of context on memory is the study of Godden and Baddeley (1980), who manipulated context by having deep-sea divers learn and retrieve word lists on dry land or underwater. Their results demonstrated an encoding specificity effect, indicating that remembering word lists learned underwater was better when a recall test was performed under water as well, and that the same effect existed for words learned and tested on dry land. With regard to the auditory characteristics, Grant et al. (1998) found that retrieval performance was better in the matching auditory conditions between learning and test session (silent-silent and noisynoisy) than in the mismatching auditory conditions (silent-noisy or noisy-silent). In addition to visual and auditory contextual cues, Suss et al. (2012) demonstrated that olfactory contextual cues can also affect learning performance.

Consistent with the CLT perspective, negative effects of physical environmental factors imposing an extraneous load on WM should always be minimized or, if possible, eliminated. Although learners are able to exclude irrelevant environmental stimuli from the information processing cycle themselves by an effortful suppression process, this process imposes a load on the executive component of WM and can better be prevented (E. E. Smith and Jonides 1999). With regard to the context-dependence of learning, the context in which learning takes place should preferably mimic the context in which it is tested; if this is not possible, learning best takes place in a variety of contexts so that transfer to new contexts is facilitated (Paas and Van Merriënboer 1994b).

\section{Physiological Effects of the Physical Learning Environment}

Aspects of the physical environment may affect cognitive load and learning through physiological factors. An example of such an effect is provided by the effect of the thermal condition of the physical learning environment on performance through the arterial blood oxygen saturation. The amount of arterial blood oxygen saturation is positively related to the quality of cognitive performance (e.g., Scholey et al. 1999). Based on studies into the negative effects of acute and chronic exposures to hypoxia (e.g., oxygen deprivation during high-altitude mountaineering) on human learning and cognition (e.g., Kramer et al. 1993), we can assume that the quality of the air and the thermal conditions of a learning environment can affect an individual's learning performance through oxygen-related physiological mechanisms. This assumption was, amongst others, supported by a study of Lan et al. (2011), who found that in a warm office environment (at $30^{\circ} \mathrm{C}$ ), participants had a lower arterial oxygen saturation and were less willing to exert effort than in a thermally neutral office environment $\left(\right.$ at $22^{\circ} \mathrm{C}$ ). Another example of a direct physiological effect of the environment is related to the effects of food on the blood glucose level. Elevated blood glucose, for example through a glucose drink, is associated with an improvement on a number of cognitive tasks, particularly those that require effortful mental processing (e.g., Scholey et al. 2001). The positive relationship between blood glucose level, blood oxygen saturation, and cognitive performance can be explained by the brain's metabolic need to accommodate the increased need for more oxygen and glucose by task-sensitive neural mechanisms during an effortful cognitive processing (Scholey et al. 1999; Turner and Carroll 1985). 
It seems clear that the effects of the thermal condition of the learning environment may have a direct physiological impact on cognitive performance. However, for other factors, it is much less obvious whether their impact on cognition is physiological or mediated by other processes. One example of such a factor is the lighting of the learning environment. Several studies have shown that the color temperature of the lamps (e.g., warm-white vs. cool-white) and the level of luminance (e.g., 300 vs. 1,500 Lx) have an impact on cognitive performance (e.g., Hygge and Knez 2001; Knez and Hygge 2002). This impact, however, may be physiological but may also be explained by affective mood changes.

\section{Affective Effects of the Physical Learning Environment}

The effects of the physical learning environment on learning can be considered from its affective influences on the learner. We can assume that a good quality of the physical learning environment (e.g., fresh air and well-managed temperature in a classroom) may have a positive effect on learners' affect, their willingness to invest mental effort, and consequently on learning. This perspective assumes that emotional state, mood, or motivation act as a mediator of the relationship between the physical learning environment and learning performance (e.g., Erez and Isen 2002; Uline and Tschannen-Moran 2008). Evans and Lepore (1993) provide evidences of non-auditory effects of noise on childrens' affect and learning performance. For example, in a noisy classroom environment, children are more likely to give up on a puzzle task than children in a quiet classroom environment (Cohen et al. 1980). Evans and Stecker (2004) also showed that noise can lead to diminished motivation, feelings of helplessness, and consequently result in lower learning outcomes.

With regard to the symbolic meaning of specific physical features of the learning environment, the construal level theory perspective (e.g., Trope and Liberman 2010) provides interesting evidence of the effect of spatial distance in learning. There is empirical evidence that people tend to use a more abstract mental representation strategy when judging, perceiving, and recognizing distal objects or events; proximal objects or events, in turn, are represented by more concrete mental representations (Bar-Anan et al. 2006; Fujita et al. 2006). Jia et al. (2009), for instance, investigated the effect of spatial distance on creative cognition and insight problem solving. In two experiments, participants assigned to either a spatially near or distant group were asked to perform a problem-solving task and informed whether the tasks were developed from a far or close location. When a creative task was assigned from a far rather than a close distance, participants provided more creative responses and performed better on a problem-solving task requiring creative insight. Some contextual aspects of the distance thus seem to play a role in the relationship between the social meaning of the physical learning environment characteristics and cognitive performance.

With regard to the meaning of spatial distance in diverse classroom settings, it is known that people select seats in ways that enable them to use physical distance as a strategy to maintain social distance (e.g., Gump 1980; Mehrabian 1969; Schwebel and Cherlin 1972). Studies on the influence of seating arrangements in classrooms showed that learners assigned to the front row and the center of each row participated more (e.g., Montello 1988; Sommer 1967) and were more attentive to learning activities (e.g., Marx et al. 1999) than peers in the middle and back rows and peers at the side of each row. A recent study conducted by Adam and Galinsky (2012) showed that physical features (i.e., symbolic meaning of clothing) can affect learners' cognitive performances. Participants who wore a lab coat performed better on selective attention tasks than participants who wore their regular cloths.

CLT provides a theoretical framework for understanding such affective influences of specific characteristics of the physical learning environment. In the original model, Paas and 
van Merriënboer (1994a) mentioned that the subject-task (environment) interactions can affect cognitive load through relatively unstable factors such as motivation of learners. With regard to the current motivational perspective of cognitive load (e.g., Paas et al. 2005), the poor physical learning environment may influence learners' emotional states such as feeling of discomfort and consequently reduce learners' willingness to allocate cognitive resources to the learning task and negatively impact learning. A well-managed or high-quality physical learning environment, in turn, can be expected to have a positive effect on the learners' willingness to allocate cognitive resources to the learning task and positively impact learning. Recent studies conducted by Fraser and colleagues (Fraser et al. 2011; Fraser et al. 2012; see also Smith and Ayres this issue) provide an empirical support for the effect of emotions on cognitive load. During a simulation learning session in a medical school, students who experienced the simulated death of a manikin experienced higher cognitive load than students whose manikin survived. With regard to the effect of emotional designs of learning materials on cognitive load, Um and colleagues (2012; see also Plass et al. 2013) found that the use of an esthetically appealing design in multimedia learning materials (e.g., use of a face-like pedagogical agent) led to positive emotions and reduced the perceived difficulty of the learning task.

With regard to the learners' anxiety, existing studies show that specific types of learning and test environments can make students anxious. This anxiety impairs efficient functioning of attention, and may lead to intrusive thoughts about failure in WM, thereby taking WM capacity away from performing on the main task (Eysenck and Calvo 1992; Eysenck et al. 2007). Hancock (2001) found that students performed poorly and were less motivated when exposed to highly evaluative classrooms and that this effect was more pronounced for testanxious students. Beilock et al. (2010) showed that the math anxiety of female elementary school teachers carries negative consequences for the math achievement of their female students. They found a positive relationship between the anxiousness of the teacher about math and the likeliness that girls endorse the commonly held stereotype that "boys are good at math, and girls are good at reading". In addition, the girls who endorsed this stereotype showed less math learning across the school year. If we consider the school teacher as a part of the learning environment, it is clear that the learning environment can affect the students' anxiety, cognitive load, and learning.

\section{Managing Cognitive Load by Changing the Physical Environment}

If we accept that the physical learning environment is an independent source of WM load for learners, it can be manipulated to manage learners' cognitive load and so improve learning. Our new model (Fig. 2) shows that both two-way and three-way interactions between the three causal factors of cognitive load (i.e., physical environment, task, and learner) should be considered. These interactions complement known cognitive load effects and may provide researchers with novel perspectives on their findings.

\section{E×T: Interactions Between the Physical Environment and the Task}

Interactions between the physical environment and the learning task might first indicate that the effectiveness of instructional techniques (e.g., solving problems vs. studying worked examples) can be different depending on the characteristics of the physical learning environment (e.g., level of noise). In turn, they might also indicate that specific changes in the physical learning environment (e.g., colors of the wall) in order to manage cognitive load have different or even reversed effects depending on the type of task (e.g., creative problem solving vs. a memory span task). 
With regard to the worked example effect (Paas and Van Merriënboer 1994b; Van Gerven et al. 2002), which refers to the finding that novice students learn less from solving conventional problems than from studying equivalent worked out problem solutions, it would be interesting to study whether there are more or less suitable physical learning environments for either studying worked examples or solving the equivalent problems. Possibly, the disadvantage of problem solving may be compensated by manipulating specific characteristics of the physical learning environment. The anecdote of Grigori Perelman fits this perspective. This world-famous mathematician won the Field Medal (but refused it) for solving one of the biggest problems in mathematics known as the Poincaré conjecture. In order to solve this problem, he went into the woods because, according to him, this environment facilitated creative problem solving.

Existing studies focusing on the effect of the specific characteristics of physical learning environments on creative problem solving provide some further evidence. McCoy and Evans (2002) studied the influence of the physical learning environment on innovative thought. They hypothesized that there are certain characteristics of the physical environment that people prefer when working on a specific task. They identified several environmental characteristics that were believed to facilitate creative performance, including the complexity of visual details, a natural environment (cf. Perelman's woods), the use of natural materials, and a limited use of cool colors. As expected, their study showed positive effects of these characteristics on the level of creative performance. In a similar vein, Zhu and colleagues proposed that different types of cognitive tasks (i.e., detailed/specific tasks vs. creative tasks) might be activated by different colors (red vs. blue; Mehta and Zhu 2009), levels of noise (moderate (70 dB) vs. high $(85 \mathrm{~dB}) /$ low $(50 \mathrm{~dB})$ ); Mehta et al. 2012), and height of the ceiling (high vs. low; MeyersLevy and Zhu 2007). They showed that blue color, moderate noise, and a high ceiling enhance performance on a creative task, whereas a red color, low noise, and a low ceiling enhance performance on a detailed/specific task. With regard to the ceiling height of the room, they found that a high ceiling activates freedom-related concepts and improves relational processing and a low ceiling activates confinement-related concepts and improves item-specific processing. In their experiments, ceiling height of two of the rooms was lowered from 10 to $8 \mathrm{ft}$. With regard to the effect of colors, they conducted series of studies about the effect of different colors on different cognitive task performances. In a memory task or proofreading task, participants in the red condition performed better than in the blue condition, and it was reversed for a creative task. They explained that red and blue colors can induce learner's alternative motivations; red color (reminiscent of stop signs or warnings) activates an avoidance motivation and can enhance performance on a detail-oriented task, blue color (reminiscent of ocean or sky), by contrast, activates an approach motivation and can enhance performance on a creative task. With regard to the level of noise, they found that increasing levels of noise induce distraction, which induces a higher construal level and abstract processing, and consequently enhances creativity. However, more interestingly, although both moderate and high levels of noise lead to a more abstract processing as compared to a low noise level, enhanced creativity was only observed in moderate noise levels because very high levels of noise reduce the extent of information processing. Based on these findings, it can be argued that the typical classroom (i.e., a quiet or clamorous room with a relatively low ceiling) is not the most beneficial environment for creative problem solving and that creativity may be facilitated in a more desirable physical environment. The findings of Mehta et al. (2012) have actually been implemented in a web/mobile application that can add a desirable level of white noise (e.g., sounds of a café) to the environment in order to facilitate creative thinking (see: http://www.coffitivity.com). 
At first sight, the positive effect of a moderate level of noise on creative tasks seems to be in conflict with the notion of reducing extraneous load. Yet, in the context of CLT, it could also be related to the presence of seductive details. Whereas some seductive details are part of the instructional design (illustrations, sound effects etc.) and should thus be seen as aspects of the task, others are not part of the instructional design and not associated with the learning objectives. Although the latter type of seductive details is part of the physical environment, it may still influence cognitive load and learning. In a review by Rey (2012), it has been argued that some seductive details might attract attention and increase extraneous cognitive load, while others may enhance learners' interests and help them to invest more mental effort (cf. 'desirable difficulties'; Bjork 1994) — even when they also impose an extraneous load. Moderate noise might possibly be seen as a seductive detail or desirable difficulty helping learners to invest more effort in learning. Future research into seductive details is needed to find out whether they can indeed have differential effects on cognitive load and learning. In addition, it can be argued that the effectiveness of desirable difficulty (i.e., extraneous load) can differ depending on the types of task (e.g., math problem solving vs. brainstorming). The interaction between task characteristic and the physical learning environment will be discussed in next section.

\section{E $\times$ L: Interactions Between the Physical Environment and the Learner}

Consistent with the "person-environment fit account" (e.g., Nielsen and Moos 1978), researchers found a close relationship between the preferred learning environment of a learner and his or her achievement in this environment; learners perform higher in a preferred environment compared to a non-preferred environment (Hattie and Watkins 1988; Wong and Watkins 1996). Interestingly, Wong and Watkins (1996) also found that the impact of the learner-environment fit was more salient among low self-monitoring individuals than among high self-monitoring individuals, supposedly because the latter can more easily adapt themselves to different situations. It is conceivable that similar interactions can be found between learners' expertise and characteristics of the environment (cf. the expertise-reversal effect). For simulator-based learning, for example, it can be argued that highly experienced learners learn best in a high-fidelity environment with lots of irrelevant details (because they can ignore the irrelevant details and profit from the resemblance between the simulated environment and the real environment), whereas less experienced learners learn best in a lower fidelity environment with much less irrelevant details (because they cannot ignore these details; Kirschner and Van Merriënboer 2013).

With regard to learners' anxiety, Dowaliby and Schumer (1973) compared university students' anxiety in a learner-centered vs. teacher-centered environment. They found a crossover interaction, showing that high-anxious students perform better in a teacher-centered environment, whereas low-anxious students perform better in a learner-centered environment. Their results may support the notion of the learner-environment fit in that a learner-centered environment for low-anxious students fits a circle or square seating arrangement, whereas a teacher-centered environment for high-anxious students fits a frontal or rows seating arrangement.

More generally, previous studies demonstrated that specific learner characteristics such as age, gender, and prior knowledge can make a learner more sensitive to the environment. It is widely accepted that young learners are more sensitive to the impact of the physical learning environment than adults. Doherty-Sneddon et al. (2002), for instance, found that primary school children below the age of 8 years cannot manage their cognitive processing resources as effectively as older children when the environment becomes more demanding. More 
specifically, in contrast to young children, older children and adults (Glenberg et al. 1998) look away more often from the face of their instructor when answering difficult as opposed to easy questions. Moreover, in its widest sense, cultural differences can also affect learner characteristics mediating the influence of the physical environment on learning. It has been pointed out that typical physical settings of classroom such as lighting conditions or seating arrangements vary between countries depending on the philosophies of education (Alexander 2001). In this regards, Mehta and Zhu (2009) also mentioned that the effect of the same color on the cognitive task may have different associations across cultures (e.g., red is associated with happiness in China, but with excitement and danger in the USA).

\section{$E \times T \times L:$ Interactions Between the Physical Environment, the Task, and the Learner}

A possible example of a three-way interaction can be deduced from studies on gender- and age-related effects of indoor lighting on mood and cognitive performance (e.g., Knez and Enmarker 1998; Knez and Kers 2000). Knez and Kers (2000) found that the color temperature of indoor lighting differentially affected mood and cognitive performance as a function of gender and age. Whereas younger adults best preserved a negative mood in "warm" white lighting, the same effect was found with "cool" white lighting for older adults. If we assume a positive relationship between mood and willingness to invest cognitive resources (the more positive a learner's mood, the more willing he/she is to invest cognitive resources; see e.g., Paas et al. 2005), it can be speculated that these effects could interact with task complexity, in such a way that under warm white lighting conditions, younger adults perform better on complex tasks than under cool white lighting conditions, whereas for the older adults the opposite effect can be expected.

One well-known interaction in cognitive load research is the expertise-reversal effect (Kalyuga et al. 2012). This effect indicates that novice learners in a domain learn more from studying worked examples than from solving the equivalent problems, whereas more experienced learners in a domain learn more from solving problems than from studying the equivalent worked examples. The question is then whether manipulations of the physical learning environment that further strengthen the value of worked examples for novice learners will be different from manipulations that further strengthen the value of problem solving for experienced learners? Coming back to the anecdote about Grigori Perelman: as a genius in the field of mathematics, his creative problem solving profited from going into the woods. Yet, it is well conceivable that for a novice student in the field of mathematics, the study of worked examples might profit more from working in a classroom with as little distractions as possible than from going into the woods. Although we are not familiar with existing research on such three-way interactions, they open up a new research agenda for cognitive load researchers. This is especially true when this research starts from task-learner interactions for which already ample empirical evidence exists, such as the expertise-reversal effect.

Another recently identified cognitive load effect, which is related to the distributed cognition paradigm, is called the collective working memory effect (F. Kirschner et al. 2009, 2011a). The effect can be used to provide an example of a possible three-way interaction. The collective working memory effect occurs when individuals experience lower cognitive load and obtain higher learning outcomes through collaborative work than when learning alone. Interestingly, working collaboratively or individually can be considered as a variation of the physical environment. F. Kirschner et al. (2009, 2011a) showed that a group of learners can be considered as a collection of cooperating working memories, which enables learners to share the working memory load and perform better on complex cognitive tasks than individual 
learners. In addition, they showed that on simple learning tasks, individual learners showed higher learning outcomes than collaborative learners, due to the relatively high cognitive costs of communicating about issues that could be dealt with quite easily by an individual, so without communication. In one study, F. Kirschner et al. (2011b) showed that novice learners achieved higher learning outcomes when they had to solve problems collaboratively in the learning phase than when they had to study worked examples collaboratively during the learning phase. For individual learners, the opposite effect was found. Interestingly, Retnowati et al. (2010) conducted a similar study and showed that groups could benefit more from learning from worked examples rather than problem solving. These studies can be considered as reflecting a two-way interaction between learning-task characteristics (worked example study vs. problem solving) and the physical learning environment (individually vs. collaboratively). It would be interesting to add a learner characteristic, such as learner expertise, to those studies to explore possible three-way interactions.

\section{Discussion}

Until now, CLT researchers paid very little attention to the effects of the physical learning environment on cognitive load and learning. In experiments, the physical environment is typically treated as a control variable that is best kept constant. The major purpose of this paper was to support our claim that the physical learning environment should be regarded as a distinct causal factor of cognitive load, interacting with both learner characteristics and learning-task characteristics. We presented a revised model of the construct of cognitive load (Fig. 2), which identified interrelated influences of three distinct causal factors on cognitive load. Our key question is not only if causal relationships exist between the physical environment, learning, and performance but also whether the influence of the physical learning environment can be explained by a cognitive load perspective and whether the design of the physical learning environment can positively affect cognitive load and learning. CLT essentially argues that managing learners' cognitive load is a key issue for learning due to the capacity and duration limits of human WM. From the perspective of CLT, if the physical environmental is a causal factor of cognitive load, it can play a role in the management of cognitive load and thus be regarded as a determinant for learning and performance.

With regard to theoretical implications of the new model of cognitive load, CLT is extended by including the physical learning environment as a distinct causal factor of cognitive load. However, the significance of this extension can only be shown by empirical studies revealing interactions between the physical learning environment and the characteristics of the learner and/or the learning task. A new line of research is needed to test the new model and to determine the impact of the physical learning environment on cognitive load, learning processes, and performance. Adopting the concept of the learning efficiency of CLT (see Paas et al. 2005; Paas and Van Merriënboer 1993), the specific physical learning environment can be regarded as cognitively efficient if a higher performance is attained with a lower invested mental effort.

What is yet missing are studies directly testing whether specific features of the physical learning environment can be used to manage cognitive load in learning, either by reducing extraneous load or increasing germane load. Cognitive load measurement can be used to identify more direct and short-term cognitive responses to the existing physical learning environment, which is distinguishing them from the effects possibly caused by other factors, such as slower physiological processes. Interestingly, the identification of the physical learning environment as a causal factor of cognitive load may also shed new light on the concept of 
germane load. The newer conception of germane load, defining it as-germaneworking memory resources allocated to dealing with intrinsic cognitive load (Kalyuga 2011; Sweller 2010), is typically believed to increase intrinsic load by adding interactive elements (e.g., from LTM or the context) to WM. If it is true that the physical environment can also impose a germane cognitive load, for example by introducing a moderate level of noise (Mehta et al. 2012), this new conceptualization of germane load might need to be reconsidered, because it seems unlikely that noise increases the number of interacting elements in WM.

Another interesting question is whether the new model of cognitive load is consistent with an evolutionary explanation of WM (see Paas and Sweller 2012; Sweller 2008). Geary (2008) makes a distinction between biologically primary knowledge which evolved over many generations in order to survive in our environment (e.g., learning to speak) and biologically secondary knowledge which is a culturally important knowledge that we have not specifically evolved to acquire (e.g., learning mathematics). Biologically primary knowledge is much less affected by WM limitations than biologically secondary knowledge. Paas and Sweller (2012) have suggested that several cognitive load effects rely on biologically primary knowledge being used to facilitate the acquisition of biologically secondary knowledge. An example of such an effect can be found in collaborative learning environments, in which learners use the biologically primary skill of communicating to share the total cognitive load imposed by the learning task among each other (Paas and Sweller 2012). Similar mechanisms may play a role in the "survival processing paradigm" (e.g., Nairne and Pandeirada 2010; Otgaar and Smeets 2010). In this paradigm, participants' retention is tested after they have processed information in terms of its relevance to fitness-based scenarios. Nairne and Pandeirada (2010; see also Weinstein et al. 2008), for example, showed that participants remember information better after processing its relevance in an ancestral environment (the grasslands) than in a modern urban environment (the city). Although cognitive load was not measured in these studies, it may be speculated that the ancestral environment imposed a lower load on WM than the modern environment.

There are several limitations of the current study, which are mainly related to its restricted scope and limited range of examples used to substantiate the role of the physical environment in cognitive load and learning. With regard to the restricted scope, this article, for example, only focused on short-term effects of the physical environment on learning. Yet, there might be long-term effects as well, especially considering learners' physiological responses to the physical environment. For example, existing studies have shown that long-term exposure to heavy metals or toxic materials negatively affects a child's cognitive development such as IQ (e.g., Evans 2006; Needleman et al. 1979). More recently, Hong et al. (2013) found that environmental exposure to Bisphenol A can impact learning disability. In 1,089 children aged 8-10 years, urinary levels of Bisphenol A were negatively associated with the learning quotient from the scale of learning disability. With regard to the limited range of examples, we think that this reflects the current status of the field of educational research, which makes it difficult to find well-controlled studies that can be used to illustrate the role of the physical environment on cognitive load and learning. Clearly more research is needed.

To sum up, we argued in this article that there are strong arguments to treat the physical learning environment as a separate factor influencing cognitive load and learning. A new model of cognitive load has been presented, making clear that changes in the physical learning environment may moderate the effects of instruction and its influence on cognitive load and learning. This new model opens up a new research line for CLT and may eventually have not only theoretical but also important practical implications for the design of learning environments. 


\section{References}

Adam, H., \& Galinsky, A. D. (2012). Enclothed cognition. Journal of Experimental Social Psychology, 48, $918-$ 925. doi:10.1016/j.jesp.2012.02.008.

Alexander, R. J. (2001). Culture and pedagogy: international comparisons in primary education. Oxford: Blackwell.

Anderson, B. L., \& Winawer, J. (2005). Image segmentation and lightness perception. Nature, 434, 79-83. doi: 10.1038/nature03271.

Ayres, P. (1993). Why goal-free problems can facilitate learning. Contemporary Educational Psychology, 18, 376-381. doi:10.1006/ceps.1993.1027.

Ayres, P., \& Paas, F. (2012). Cognitive load theory: new directions and challenges. Applied Cognitive Psychology, 26, 827-832. doi:10.1002/Acp.2882.

Bar-Anan, Y., Liberman, N., \& Trope, Y. (2006). The association between psychological distance and construal level: evidence from an implicit association test. Journal of Experimental Psychology, 135, 609. doi:10.1037/ 0096-3445.135.4.609.

Beer, R. D. (2000). Dynamical approaches to cognitive science. Trends in Cognitive Sciences, 4, 91-99. doi:10. 1016/S1364-6613(99)01440-0.

Beilock, S. L., Gunderson, E. A., Ramirez, G., \& Levine, S. C. (2010). Female teachers' math anxiety affects girls' math achievement. Proceedings of the National Academy of Sciences, 107, 1860-1863. doi:10.1073/ pnas.0910967107.

Bjork, R. A. (1994). Memory and metamemory considerations in the training of human beings. In J. Metcalfe \& A. Shimamura (Eds.), Metacognition: knowing about knowing (pp. 185-205). Cambridge, MA: MIT Press.

Clark, A., \& Chalmers, D. (1998). The extended mind. Analysis, 58, 7-19. doi:10.1093/analys/58.1.7.

Cohen, S., Evans, G. W., Krantz, D. S., \& Stokols, D. (1980). Physiological, motivational, and cognitive effects of aircraft noise on children: moving from the laboratory to the field. American Psychologist, 35, 231-243. doi:10.1037/0003-066X.35.3.231.

Cowan, N. (2001). The magical number 4 in short-term memory: a reconsideration of mental storage capacity. Behavioral and Brain Sciences, 24, 87-114. doi:10.1017/S0140525X01003922.

Dillenbourg, P., \& Traum, D. (1997). The role of a whiteboard in a distributed cognitive system. Paper presented at the Swiss workshop on collaborative and distributed systems, Lausanne, Switzerland, May 1st 1997. Retrieved on January, 15, 2014. from http://citeseerx.ist.psu.edu/viewdoc/download?doi=10.1.1.21. $1042 \&$ rep $=$ rep $1 \&$ type $=$ pdf

Doherty-Sneddon, G., \& Phelps, F. G. (2005). Gaze aversion: a response to cognitive or social difficulty? Memory \& Cognition, 33, 727-733. doi:10.3758/BF03195338.

Doherty-Sneddon, G., Bruce, V., Bonner, L., Longbotham, S., \& Doyle, C. (2002). Development of gaze aversion as disengagement from visual information. Developmental Psychology, 38, 438-445. doi:10. $1037 / 0012-1649.38 .3 .438$.

Dowaliby, F., \& Schumer, H. (1973). Teacher-centered versus student-centered mode of college classroom instruction as related to manifest anxiety. Journal of Educational Psychology, 64, 125. doi:10.1037/h0034590.

Erez, A., \& Isen, A. M. (2002). The influence of positive affect on the components of expectancy motivation. Journal of Applied Psychology, 87, 1055-1067. doi:10.1037/0021-9010.87.6.1055.

Evans, G. W. (2006). Child development and the physical environment. Annual Review of Psychology, 57, 423451. doi:10.1146/annurev.psych.57.102904.190057.

Evans, G. W., \& Lepore, S. J. (1993). Nonauditory effects of noise on children: a critical review. Children's Environments, 10, 31-51. doi:10.2307/41515250.

Evans, G. W., \& Stecker, R. (2004). Motivational consequences of environmental stress. Journal of Environmental Psychology, 24, 143-165. doi:10.1016/S0272-4944(03)00076-8.

Eysenck, M. W., \& Calvo, M. G. (1992). Anxiety and performance - the processing efficiency theory. Cognition \& Emotion, 6, 409-434. doi:10.1080/02699939208409696.

Eysenck, M. W., Derakshan, N., Santos, R., \& Calvo, M. G. (2007). Anxiety and cognitive performance: attentional control theory. Emotion, 7, 336-353. doi:10.1037/1528-3542.7.2.336.

Fraser, K., Huffman, J., Ma, I., Wright, B., Mcllwrick, J., \& McLaughlin, K. (2011). Death of a manikin: adverse effects on learning and mechanisms. CHEST Journal, 140, 1024A-1024A. doi: 10.1378/chest. 1112887 .

Fraser, K., Ma, I., Teteris, E., Baxter, H., Wright, B., \& McLaughlin, K. (2012). Emotion, cognitive load and learning outcomes during simulation training. Medical Education, 46, 1055-1062. doi:10.1111/j.1365-2923. 2012.04355.x.

Fujita, K., Henderson, M. D., Eng, J., Trope, Y., \& Liberman, N. (2006). Spatial distance and mental construal of social events. Psychological Science, 17, 278-282. doi:10.1111/j.1467-9280.2006.01698.x. 
Geary, D. C. (2008). An evolutionarily informed education science. Educational Psychologist, 43, 179-195. doi: 10.1080/00461520802392133.

Gisselgard, J., Petersson, K. M., Baddeley, A. D., \& Ingvar, M. (2003). The irrelevant speech effect: a PET study. Neuropsychologia, 41, 1899-1911. doi:10.1016/S0028-3932(03)00122-2.

Gisselgard, J., Petersson, K. M., \& Ingvar, M. (2004). The irrelevant speech effect and working memory load. NeuroImage, 22, 1107-1116. doi:10.1016/j.neuroimage.2004.02.031.

Glenberg, A. M., Schroeder, J. L., \& Robertson, D. A. (1998). Averting the gaze disengages the environment and facilitates remembering. Memory \& Cognition, 26, 651-658. doi:10.3758/BF03211385.

Godden, D., \& Baddeley, A. D. (1980). When does context influence recognition memory? British Journal of Psychology, 71, 99-104. doi:10.1111/j.2044-8295.1980.tb02735.x.

Grant, H. M., Bredahl, L. C., Clay, J., Ferrie, J., Groves, J. E., McDorman, T. A., \& Dark, V. J. (1998). Contextdependent memory for meaningful material: information for students. Applied Cognitive Psychology, 12, 617-623. doi:10.1002/(SICI)1099-0720(1998120)12:6<617::AID-ACP542>3.0.CO;2-5.

Gump, P. V. (1980). The school as a social situation. Annual Review of Psychology, 31, 553-582. doi:10.1146/ annurev.ps.36.020185.000555.

Hancock, D. R. (2001). Effects of test anxiety and evaluative threat on students' achievement and motivation. Journal of Educational Research, 94, 284-290. doi:10.1080/00220670109598764.

Hattie, J., \& Watkins, D. (1988). Preferred classroom environment and approach to learning. British Journal of Educational Psychology, 58, 345-349. doi:10.1111/j.2044-8279.1988.tb00910.x.

Higgins, S., Hall, E., Wall, K., Woolner, P., \& McCaughey, C. (2005). The impact of school environments: a literature review. The Centre for Learning and Teaching, School of Education, Communication and Language Science, University of Newcastle. Retrieved on February, 16, 2014. from http://www.ncl.ac.uk/ cflat/news/DCReport.pdf.

Hong, S. B., Hong, Y. C., Kim, J. W., Park, E. J., Shin, M. S., Kim, B. N., et al. (2013). Bisphenol A in relation to behavior and learning of school-age children. Journal of Child Psychology and Psychiatry, 54, 890-899. doi:10.1111/jcpp. 12050 .

Hygge, S., \& Knez, I. (2001). Effects of noise, heat and indoor lighting on cognitive performance and selfreported affect. Journal of Environmental Psychology, 21, 291-299. doi:10.1006/jevp.2001.0222.

Jamieson, P., Fisher, K., Gilding, T., Taylor, P. G., \& Trevitt, A. C. F. (2000). Place and space in the design of new learning environments. Higher Education Research and Development, 19, 221-236. doi:10.1080/ 072943600445664.

Jia, L., Hirt, E. R., \& Karpen, S. C. (2009). Lessons from a faraway land: the effect of spatial distance on creative cognition. Journal of Experimental Social Psychology, 45, 1127-1131. doi:10.1016/j.jesp.2009.05.015.

Kalyuga, S. (2011). Cognitive load theory: how many types of load does it really need? Educational Psychology Review, 23, 1-19. doi:10.1007/s10648-010-9150-7.

Kalyuga, S., Ayres, P., Chandler, P., \& Sweller, J. (2003). The expertise reversal effect. Educational Psychologist, 38, 23-31. doi:10.1207/S15326985ep3801_4.

Kalyuga, S., Rikers, R., \& Paas, F. (2012). Educational implications of expertise reversal effects in learning and performance of complex cognitive and sensorimotor skills. Educational Psychology Review, 24, 313-337. doi:10.1007/s10648-012-9195-x.

Kirschner, F., Paas, F., \& Kirschner, P. A. (2009). A cognitive load approach to collaborative learning: united brains for complex tasks. Educational Psychology Review, 21, 31-42. doi:10.1007/s10648-008-9095-2.

Kirschner, F., Paas, F., \& Kirschner, P. A. (2011a). Task complexity as a driver for collaborative learning efficiency: the collective working-memory effect. Applied Cognitive Psychology, 25, 615-624. doi:10.1002/acp.1730.

Kirschner, F., Paas, F., Kirschner, P. A., \& Janssen, J. (2011b). Differential effects of problem-solving demands on individual and collaborative learning outcomes. Learning and Instruction, 21, 587-599. doi:10.1016/j. learninstruc.2011.01.001.

Kirschner, P. A., \& Van Merriënboer, J. J. G. (2013). Do learners really know best? Urban legends in education. Educational Psychologist, 48, 169-183. doi:10.1080/00461520.2013.804395.

Knez, I., \& Enmarker, I. (1998). Effects of office lighting on mood and cognitive performance and a gender effect in work-xrelated judgment. Environment and Behavior, 30, 553-567. doi:10.1177/001391659803000408.

Knez, I., \& Kers, C. (2000). Effects of indoor lighting, gender, and age on mood and cognitive performance. Environment and Behavior, 32, 817-831. doi:10.1177/0013916500326005.

Knez, I., \& Hygge, S. (2002). Irrelevant speech and indoor lighting: effects on cognitive performance and selfreported affect. Applied Cognitive Psychology, 16, 709-718. doi:10.1002/acp.829.

Kramer, A. F., Coyne, J. T., \& Strayer, D. L. (1993). Cognitive function at high-altitude. Human Factors, 35, 329-344. doi:10.1177/001872089303500208.

Lan, L., Wargocki, P., Wyon, D. P., \& Lian, Z. (2011). Effects of thermal discomfort in an office on perceived air quality, SBS symptoms, physiological responses, and human performance. Indoor Air, 21, 376-390. doi:10. 1111/j.1600-0668.2011.00714.x. 
Leppink, J., Paas, F., Van der Vleuten, C. P. M., Van Gog, T., \& Van Merriënboer, J. J. G. (2013). Development of an instrument for measuring different types of cognitive load. Behavioral Research Methods, 45, 10581072. doi:10.3758/s13428-013-0334-1.

Leppink, J., Paas, F., Van Gog, T., Van der Vleuten, C. P. M., \& Van Merriënboer, J. J. G. (2014). Effects of pairs of problems and examples on task performance and different types of cognitive load. Learning and Instruction, 30, 32-42. doi:10.1016/j.learninstruc.2013.12.001.

Marks, L. E., Shepard, T. G., Burger, K., \& Chakwin, E. M. (2012). Flavor-intensity perception: effects of stimulus context. Physiology \& Behavior, 105, 443-450. doi:10.1016/j.physbeh.2011.08.039.

Marx, A., Fuhrer, U., \& Hartig, T. (1999). Effects of classroom seating arrangements on children's questionasking. Learning Environments Research, 2, 249-263. doi:10.1023/A:1009901922191.

McCoy, J. M., \& Evans, G. W. (2002). The potential role of the physical environment in fostering creativity. Creativity Research Journal, 14, 409-426. doi:10.1207/S15326934CRJ1434_11.

Mehrabian, A. (1969). Significance of posture and position in the communication of attitude and status relationships. Psychological Bulletin, 71, 359-372. doi:10.1037/h0027349.

Mehta, R., \& Zhu, R. J. (2009). Blue or red? Exploring the effect of color on cognitive task performances. Science, 323, 1226-1229. doi:10.1126/science.1169144.

Mehta, R., Zhu, R. J., \& Cheema, A. (2012). Is noise always bad? Exploring the effects of ambient noise on creative cognition. Journal of Consumer Research, 39, 784-799. doi:10.1086/665048.

Mendell, M. J., \& Heath, G. A. (2005). Do indoor pollutants and thermal conditions in schools influence student performance? A critical review of the literature. Indoor Air, 15, 27-52. doi:10.1111/j.1600-0668.2004.00320.x.

Meyers-Levy, J., \& Zhu, R. J. (2007). The influence of ceiling height: the effect of priming on the type of processing that people use. Journal of Consumer Research, 34, 174-186.

Miller, G. (1956). The magical number seven, plus or minus two: some limits on our capacity for processing information. Psychological Review, 63, 81-97. doi:10.1037/h0043158.

Montello, D. R. (1988). Classroom seating location and its effect on course achievement, participation, and attitudes. Journal of Environmental Psychology, 8, 149-157. doi:10.1016/S0272-4944(88)80005-7.

Moreno, R., \& Mayer, R. E. (2000). A coherence effect in multimedia learning: the case for minimizing irrelevant sounds in the design of multimedia instructional messages. Journal of Educational Psychology, 92, 117-125. doi:10.1037//0022-0663.92.1.117.

Nairne, J. S., \& Pandeirada, J. N. S. (2010). Adaptive memory: ancestral priorities and the mnemonic value of survival processing. Cognitive Psychology, 61, 1-22. doi:10.1016/j.cogpsych.2010.01.005.

Needleman, H. L., Gunnoe, C., Leviton, A., Reed, R., Peresie, H., Maher, C., \& Barrett, P. (1979). Deficits in psychologic and classroom performance of children with elevated dentine lead levels. The New England Journal of Medicine, 300, 689-695. doi:10.1056/NEJM197903293001301.

Nielsen, H. D., \& Moos, R. H. (1978). Exploration and adjustment in high school classrooms: a study of personenvironment fit. The Journal of Educational Research, 72, 52-57. doi:10.2307/27537177.

Otgaar, H., \& Smeets, T. (2010). Adaptive memory: survival processing increases both true and false memory in adults and children. Journal of Experimental Psychology: Learning, Memory, and Cognition, 36, 1010. doi: $10.1037 / \mathrm{a} 0019402$.

Paas, F. (1992). Training strategies for attaining transfer of problem-solving skill in statistics: a cognitive-load approach. Journal of Educational Psychology, 84, 429-434. doi:10.1037/0022-0663.84.4.429.

Paas, F., Camp, G., \& Rikers, R. (2001). Instructional compensation for age-related cognitive declines: effects of goal specificity in maze learning. Journal of Educational Psychology, 93, 181. doi:10.1037/0022-0663.93.1.181.

Paas, F., Renkl, A., \& Sweller, J. (2003a). Cognitive load theory and instructional design: recent developments. Educational Psychologist, 38, 1-4. doi:10.1207/S15326985ep3801_1.

Paas, F., Renkl, A., \& Sweller, J. (2004). Cognitive load theory: instructional implications of the interaction between information structures and cognitive architecture. Instructional Science, 32, 1-8. doi:10.1023/ B:TRUC.0000021806.17516.d0.

Paas, F., \& Sweller, J. (2012). An evolutionary upgrade of cognitive load theory: using the human motor system and collaboration to support the learning of complex cognitive tasks. Educational Psychology Review, 24, 27-45. doi:10.1007/s10648-011-9179-2.

Paas, F., Tuovinen, J. E., Tabbers, H., \& Van Gerven, P. W. M. (2003b). Cognitive load measurement as a means to advance cognitive load theory. Educational Psychologist, 38, 63-71. doi:10.1207/S15326985ep3801_8.

Paas, F., Tuovinen, J. E., Van Merriënboer, J. J. G., \& Darabi, A. A. (2005). A motivational perspective on the relation between mental effort and performance: optimizing learner involvement in instruction. Educational Technology Research and Development, 53, 25-34. doi:10.1007/Bf02504795.

Paas, F., \& Van Merriënboer, J. J. G. (1993). The efficiency of instructional conditions: an approach to combine mental effort and performance measures. Human Factors, 35, 737-743. doi:10.1177/001872089303500412.

Paas, F., \& Van Merriënboer, J. J. G. (1994a). Instructional control of cognitive load in the training of complex cognitive tasks. Educational Psychology Review, 6, 351-371. doi:10.1007/bf02213420. 
Paas, F., \& Van Merriënboer, J. J. G. (1994b). Variability of worked examples and transfer of geometrical problem-solving skills: a cognitive-load approach. Journal of Educational Psychology, 86, 122-133. doi:10. 1037/0022-0663.86.1.122

Peterson, L. R., \& Peterson, M. J. (1959). Short-term retention of individual verbal items. Journal of Experimental Psychology, 58, 193-198. doi:10.1037/h0049234.

Plass, J. L., Heidig, S., Hayward, E. O., Homer, B. D., \& Um, E. (2013). Emotional design in multimedia learning: effects of shape and color on affect and learning. Learning and Instruction. doi:10.1016/j. learninstruc.2013.02.006.

Retnowati, E., Ayres, P., \& Sweller, J. (2010). Worked example effects in individual and group work settings. Educational Psychology, 30, 349-367. doi:10.180/01443411003659960.

Rey, G. D. (2012). A review of research and a meta-analysis of the seductive detail effect. Educational Research and Review, 7, 216-237. doi:10.1016/j.edurev.2012.05.003.

Rey, G. D. (2014). Seductive details and attention distraction - an eye tracker experiment. Computers in Human Behavior, 32, 133-144. doi:10.1016/j.chb.2013.11.017.

Rivlin, L. G., \& Weinstein, C. S. (1984). Educational issues, school settings, and environmental psychology. Journal of Environmental Psychology, 4, 347-364. doi:10.1016/S0272-4944(84)80005-5.

Salamé, P., \& Baddeley, A. D. (1982). Disruption of short-term memory by unattended speech: implications for the structure of working memory. Journal of Verbal Learning and Verbal Behavior, 21, 150-164. doi:10. 1016/S0022-5371(82)90521-7.

Salamé, P., \& Baddeley, A. D. (1986). Phonological factors in STM: similarity and the unattended speech effect. Bulletin of the Psychonomic Society, 24, 263-265. doi:10.3758/BF03330135.

Schneider, W., \& Shiffrin, R. M. (1977). Controlled and automatic human information processing: I. Detection, search, and attention. Psychological Review, 84, 1-66. doi:10.1037/0033-295X.84.1.1.

Scholey, A. B., Harper, S., \& Kennedy, D. O. (2001). Cognitive demand and blood glucose. Physiology \& Behavior, 73, 585-592. doi:10.1016/S0031-9384(01)00476-0.

Scholey, A. B., Moss, M. C., Neave, N., \& Wesnes, K. (1999). Cognitive performance, hyperoxia, and heart rate following oxygen administration in healthy young adults. Physiology \& Behavior, 67, 783-789. doi:10.1016/ S0031-9384(99)00183-3

Schwebel, A. I., \& Cherlin, D. L. (1972). Physical and social distancing in teacher-pupil relationships. Journal of Educational Psychology, 63, 543-550. doi:10.1037/h0034081.

Shiffrin, R. M., \& Schneider, W. (1977). Controlled and automatic human information processing: Ii. Perceptual learning, automatic attending, and a general theory. Psychological Review, 84, 127-190.

Smith, A., \& Ayres, P. (this issue). The impact of persistent pain on working memory and learning. Educational Psychology Review.

Smith, E. E., \& Jonides, J. (1999). Storage and executive processes in the frontal lobes. Science, 283, 1657-1661. doi:10.1126/science.283.5408.1657.

Smith, S. M., \& Vela, E. (2001). Environmental context-dependent memory: a review and meta-analysis. Psychonomic Bulletin \& Review, 8, 203-220. doi:10.3758/BF03196157.

Sommer, R. (1967). Classroom ecology. Journal of Applied Behavioral Science, 3, 489-503.

Suss, C., Gaylord, S., \& Fagen, J. (2012). Odor as a contextual cue in memory reactivation in young infants. Infant Behavior \& Development, 35, 580-583. doi:10.1016/j.infbeh.2012.05.004.

Sweller, J. (1988). Cognitive load during problem solving: effects on learning. Cognitive Science, 12, 257-285. doi:10.1016/0364-0213(88)90023-7.

Sweller, J. (2008). Instructional implications of David C. Geary's evolutionary educational psychology. Educational Psychologist, 43, 214-216. doi:10.1080/00461520802392208.

Sweller, J. (2010). Element interactivity and intrinsic, extraneous, and germane cognitive load. Educational Psychology Review, 22, 123-138. doi:10.1007/s10648-010-9128-5.

Sweller, J., Ayres, P., \& Kalyuga, S. (2011). Cognitive load theory (vol. 1). New York: Springer.

Sweller, J., Van Merriënboer, J. J. G., \& Paas, F. (1998). Cognitive architecture and instructional design. Educational Psychology Review, 10, 251-296. doi:10.1023/A:1022193728205.

Tanner, C. K. (2000). The influence of school architecture on academic achievement. Journal of Educational Administration, 38, 309-330. doi:10.1108/09578230010373598.

Tanner, C. K. (2008). Explaining relationships among student outcomes and the school's physical environment. Journal of Advanced Academics, 19, 444-471. doi:10.4219/jaa-2008-812.

Titchener, E. B. (1901). Experimental psychology: A manual of laboratory practice (vol. 1). New York: The Macmillan Co.

Trope, Y., \& Liberman, N. (2010). Construal-level theory of psychological distance. Psychological Review, 117, 440-463. doi:10.1037/a0018963.

Tulving, E., \& Thomson, D. M. (1973). Encoding specificity and retrieval processes in episodic memory. Psychological Review, 80, 352-373. doi:10.1037/h0020071. 
Turner, J. R., \& Carroll, D. (1985). Heart rate and oxygen consumption during mental arithmetic, a video game, and graded exercise: further evidence of metabolically-exaggerated cardiac adjustments? Psychophysiology, 22, 261-267. doi:10.1111/j.1469-8986.1985.tb01597.x.

Uline, C., \& Tschannen-Moran, M. (2008). The walls speak: the interplay of quality facilities, school climate, and student achievement. Journal of Educational Administration, 46, 55-73. doi:10.1108/09578230810849817.

Um, E., Plass, J. L., Hayward, E. O., \& Homer, B. D. (2012). Emotional design in multimedia learning. Journal of Educational Psychology, 104, 485-498. doi:10.1037/A0026609.

Van Gerven, P. W. M., Paas, F., Van Merriënboer, J. J. G., \& Schmidt, H. G. (2002). Cognitive load theory and aging: effects of worked examples on training efficiency. Learning and Instruction, 12, 87-105. doi:10. 1016/s0959-4752(01)00017-2.

Van Gerven, P. W. M., Paas, F., Van Merriënboer, J. J. G., \& Schmidt, H. G. (2006). Modality and variability as factors in training the elderly. Applied Cognitive Psychology, 20, 311-320. doi:10.1002/acp.1247.

Van Gog, T., Paas, F., \& Van Merriënboer, J. J. G. (2006). Effects of process-oriented worked examples on troubleshooting transfer performance. Learning and Instruction, 16, 154-164. doi:10.1016/j.learninstruc. 2006.02.003.

Van Merriënboer, J. J. G. (1990). Strategies for programming instruction in high school: program completion vs. program generation. Journal of Educational Computing Research, 6, 265-285. doi:10.2190/4NK5-17L7TWQV-1EHL.

Van Merriënboer, J. J. G., \& De Croock, M. B. M. (1992). Strategies for computer-based programming instruction: program completion vs. program generation. Journal of Educational Computing Research, 8 , 365-394. doi:10.2190/MJDX-9PP4-KFMT-09PM.

Van Merriënboer, J. J. G., \& Sweller, J. (2005). Cognitive load theory and complex learning: recent developments and future directions. Educational Psychology Review, 17, 147-177. doi:10.1007/s10648-005-3951-0.

Van Merriënboer, J. J. G., \& Sweller, J. (2010). Cognitive load theory in health professional education: design principles and strategies. Medical Education, 44, 85-93. doi:10.1111/j.1365-2923.2009.03498.x.

Vredeveldt, A., Hitch, G., \& Baddeley, A. D. (2011). Eyeclosure helps memory by reducing cognitive load and enhancing visualisation. Memory \& Cognition, 39, 1253-1263. doi:10.3758/s13421-011-0098-8.

Weinstein, C. S. (1979). The physical environment of the school: a review of the research. Review of Educational Research, 49, 577-610. doi:10.3102/00346543049004577.

Weinstein, Y., Bugg, J. M., \& Roediger, H. L. (2008). Can the survival recall advantage be explained by basic memory processes? Memory \& Cognition, 36, 913-919. doi:10.3758/MC.36.5.913.

Wilson, M. (2002). Six views of embodied cognition. Psychonomic Bulletin \& Review, 9, 625-636. doi:10.3758/ BF03196322.

Wong, N., \& Watkins, D. (1996). Self-monitoring as a mediator of person-environment fit: an investigation of Hong Kong mathematics classroom environments. British Journal of Educational Psychology, 66, 223-229. doi:10.1111/j.2044-8279.1996.tb01191.x. 